\title{
Regulation of oxidative stress resistance in Campylobacter jejuni, a microaerophilic foodborne pathogen
}

\author{
Jong-Chul Kim, Euna Oh, Jinyong Kim and Byeonghwa Jeon* \\ School of Public Health, University of Alberta, Edmonton, AB, Canada
}

\section{OPEN ACCESS}

Edited by:

Yi-Cheng Sun,

Chinese Academy of Medical Sciences and Peking Union Medical

College, China

Reviewed by:

Zhao Chen,

Clemson University, USA Sergio I. Martinez-Monteagudo,

The Ohio State University, USA

*Correspondence:

Byeonghwa Jeon, School of Public Health, University of Alberta, 3-57A South Academic Building, Edmonton, AB T6G 2G7,

Canada

bjeon@ualberta.ca

Specialty section:

This article was submitted to

Food Microbiology,

a section of the journal

Frontiers in Microbiology

Received: 19 May 2015

Accepted: 08 July 2015

Published: 29 July 2015

Citation:

Kim J-C, Oh E, Kim J and Jeon B (2015) Regulation of oxidative stress resistance in Campylobacter jejuni, a microaerophilic foodborne

pathogen.

Front. Microbiol. 6:751. doi: 10.3389/fmicb.2015.00751
Campylobacter jejuni is one of the leading bacterial causes of human gastroenteritis. Due to the increasing rates of human campylobacteriosis, $C$. jejuni is considered as a serious public health concern worldwide. C. jejuni is a microaerophilic, fastidious bacterium. C. jejuni must overcome a wide range of stress conditions during foodborne transmission to humans, such as food preservation and processing conditions, and even in infection of the gastrointestinal tracts of humans. Particularly, this microaerophilic foodborne pathogen must survive in the atmospheric conditions prior to the initiation of infection. C. jejuni possesses unique regulatory mechanisms for oxidative stress resistance. Lacking OxyR and SoxRS that are highly conserved in other Gram-negative foodborne pathogens, C. jejuni modulates the expression of genes involved in oxidative stress resistance mainly via the peroxide resistance regulator and Campylobacter oxidative stress regulator. Based on recent findings of ours and others, in this review, we described how $C$. jejuni regulates the expression of oxidative stress defense.

Keywords: Campylobacter jejuni, oxidative stress, stress response, regulation of gene expression, survival mechanisms

Food safety is a serious public health issue in both developed and developing countries. Consumption of food contaminated with pathogens results in gastrointestinal diseases, chronic sequelae and disability, and even death (Lindsay, 1997). Campylobacter jejuni is considered as the most common bacterial cause of acute gastroenteritis in humans (Park, 2002), and develops clinical symptoms, such as diarrhea, abdominal cramps, and fever (Altekruse et al., 1999). Also, C. jejuni is the primary cause of Guillan-Barré syndrome, an acute peripheral neuropathy (Hughes and Cornblath, 2005).

The Centers for Disease Control and Prevention (CDC) estimated that Campylobacter annually causes approximately 2.4-4 million infection cases in the US, and campylobacteriosis is the second major foodborne infection in the country (Samuel et al., 2004). In Canada, Campylobacter is the most frequent bacterial cause of acute gastrointestinal illness, accounting for approximately 0.6 million infection cases per year (Thomas et al., 2006). Worldwide, the estimated number of annual cases of human campylobacteriosis reaches up to 400-500 million (Ruiz-Palacios, 2007). Despite the enormous number of infection cases, Campylobacter infection has not been controlled, but rather exhibits a still increasing trend (CDC, 2014). In addition, the resistance of Campylobacter to clinically important antibiotics, such as fluoroquinolones, has emerged as another serious public health concern (Luangtongkum et al., 2009). In some countries, antibiotic resistance is highly prevalent in $C$. jejuni, seriously compromising the effectiveness of antimicrobial chemotherapy. For example, ciprofloxacin (an important fluoroquinolone antibiotic for humans) resistance is found in approximately $92 \%$ C. jejuni 
isolates from raw chicken in South Korea (Han et al., 2007), and $100 \%$ C. jejuni isolates from children in Thailand (Serichantalergs et al., 2007).

\section{Campylobacter Biology and Transmission}

Campylobacter sp. are isolated from a wide range of animals, such as poultry, cattle, sheep, and dogs, and most of them are associated with various disease symptoms in animals and humans (Humphrey et al., 2007). As a microaerophilic bacterium, Campylobacter requires an oxygen concentration of 3-15\%, and cannot ferment nor oxidize carbohydrates; instead, amino acids are utilized as the major energy source (Brenner and Staley, 2005). While campylobacters grow at $35-37^{\circ} \mathrm{C}$, some species, such as C. jejuni, C. coli, C. lari, C. helveticus, and C. hyointestinalis, are thermotolerant (Brenner and Staley, 2005). As a pathogenic species that is most commonly implicated in human infection (Scharff, 2012), C. jejuni is frequently isolated from poultry, possibly because the body temperature of poultry is close to the optimal growth temperature of C. jejuni (Young et al., 2007), which is $42^{\circ} \mathrm{C}$ (Hazeleger et al., 1998; Stintzi, 2003). Although C. jejuni is a thermotolerant species with an optimal growth temperature higher than that of Escherichia coli and Salmonella, C. jejuni is more sensitive to heat stress than these bacteria. The $D$-value of $C$. jejuni is $2.12 \mathrm{~min}$ at $55^{\circ} \mathrm{C}$ in ground chicken meat (Blankenship and Craven, 1982), whereas the D-values of E. coli O157:H7 and Salmonella in chicken are 8.76-9.74 min at $55^{\circ} \mathrm{C}$ and $3.2 \mathrm{~min}$ at $56^{\circ} \mathrm{C}$, respectively (Ahmed et al., 1995; Mazzotta, 2000).

Due to the commensalism of $C$. jejuni in the intestinal tracts of various animals, consumption of animal products is the leading cause of human infections with $C$. jejuni. Since poultry is the major reservoir for $C$. jejuni, this pathogenic bacterium is likely to be present in poultry wastes with an average population level of ca. $10^{5} \mathrm{CFU} / \mathrm{g}$ in fecal samples collected from broiler chicken flocks (Chen and Jiang, 2014). In particular, high levels of Campylobacter contamination in poultry meat can lead to extensive cross contamination in food processing (Jorgensen et al., 2002; Chen and Jiang, 2014). Raw meat products from other food-producing animals, such as beef, pork, and lamb, have also been implicated in the transmission of Campylobacter (Kramer et al., 2000). Whereas sporadic Campylobacter infections are frequently associated with poultry, outbreaks are often related to dairy products (Taylor et al., 2013). Unpasteurized milk is considered as a potential vehicle transmitting C. jejuni to humans (Hudson et al., 1999; Frost et al., 2002), because cattle is the second major reservoir for C. jejuni (Jonas et al., 2015). Also, many outbreak cases report that water may serve as an important environmental reservoir for Campylobacter (Bolton et al., 1982; Thomas et al., 1999), because animal feces and contaminated soil are associated with Campylobacter contamination of water (Thomas et al., 1999). Interestingly, thermotolerant Campylobacter sp., such as C. jejuni, C. coli, and C. lari, have also been isolated from seafood and shellfish (Wilson and Moore, 1996; Endtz et al.,
1997; Frost et al., 2002), and some human campylobacteriosis cases have been attributed to the consumption of raw shellfish (Endtz et al., 1997; Frost et al., 2002). Since C. jejuni is prevalent in various animals and environmental niches, this fastidious microaerophilic bacterium will be exposed to a myriad of stress conditions in both animal hosts and external environments (Murphy et al., 2006; Jackson et al., 2009). More than any other stress conditions, especially, increased oxygen tension in the atmosphere will be the most viabilitythreatening stress that $C$. jejuni cannot avoid encountering during transmission. In this review, we described current information available for the genetic/protein elements of oxidative stress resistance in C. jejuni as well as their functions and regulation.

\section{Campylobacter jejuni's Defense Against Oxidative Stress}

\section{What is Oxidative Stress?}

The oxygen concentration in the atmosphere plays a crucial role in bacterial growth in the environment. Generally, bacteria possess redox enzymes that mediate oxidative phosphorylation with oxygen molecule as an electron carrier, and the use of oxygen molecule inevitably generates reactive oxygen species (ROS), such as the superoxide anion $\left(\mathrm{O}^{2-}\right)$ and hydrogen peroxide $\left(\mathrm{H}_{2} \mathrm{O}_{2}\right)$. Subsequently, intracellular ferrous iron $\left(\mathrm{Fe}^{2+}\right)$ and $\mathrm{H}_{2} \mathrm{O}_{2}$ produce a highly reactive hydroxyl radical $(\mathrm{HO} \cdot)$ via the Fenton reaction (Storz and Imlay, 1999). If not detoxified, ROS gives deleterious effects on macromolecules in bacteria, such as DNA, membranes, and proteins (Imlay, 2003). Although bacteria possess mechanisms to maintain the homeostasis of ROS, the alteration in oxygen concentrations affects the generation rate of ROS, which leads to oxidative stress (Lushchak, 2011). Despite C. jejuni's capabilities to harmonize oxidative stress under aerobic and microaerobic conditions by utilizing various electron donors and acceptors (Jeon et al., 2010), the survival of C. jejuni is directly subject to the oxygen concentrations of its surrounding environments. According to a DNA microarray study, exposure to aerobic conditions affects biological process and gene expression in C. jejuni; particularly, the expression of genes associated with oxidative phosphorylation, antioxidation, and nucleic acid metabolism is increased by the oxygen concentration (ca. $21 \% \mathrm{O}_{2}$ ) in the atmosphere (Kaakoush et al., 2009). Described below is a list of genes/proteins that thus far have been reported to affect oxidative stress in $C$. jejuni directly or indirectly.

\section{Superoxide Stress Defense}

Superoxide dismutase (SOD) is the primary enzyme that is responsible for the detoxification of superoxide (Winterbourn et al., 1975). Whereas E. coli possesses three sod genes including $\operatorname{sod} A$, $\operatorname{sod} B$, and $\operatorname{sod} C$, which encode manganese-, iron-, and copper, zinc-cofactored SOD, respectively (Imlay, 2008), C. jejuni expresses only the iron-cofactored SodB (Pesci et al., 1994), and a $\operatorname{sodB}$ mutation increases $C$. jejuni susceptibility to both superoxide (e.g., menadione) and peroxide stress (e.g., $\mathrm{H}_{2} \mathrm{O}_{2}$ and 
cumene hydroperoxide) (Palyada et al., 2009; Flint et al., 2014). According to a two dimensional gel electrophoresis analysis (2DGE), paraquat (i.e., superoxide) exposure overexpresses Cj1371, a putative periplasmic protein, which is homologous to VacJ (virulence-associated chromosome locus J) in Shigella flexneri, and a muation of Cj1371 increases C. jejuni susceptibility to paraquat (Suzuki et al., 1994; Garénaux et al., 2008a). In S. flexneri, VacJ contibutes to the maintenance of lipid asymmetry in the outer membrane, intercellular spread, and resistance to sodium dodecyl sulfate (SDS; Carpenter et al., 2014); however, its molecular function has not been defined in C. jejuni. Bacterial motility also indirectly contributes to C. jejuni resistance to superoxide stress, as mutations of genes involved in flagellar biosynthesis and modification (e.g., motAB, $f l g R, f l h B, f l g D$, and $p s e B$ ) render $C$. jejuni significantly sensitive to menadione, a superoxide generator, and slightly to $\mathrm{H}_{2} \mathrm{O}_{2}$ (Flint et al., 2014). It would be because flagellar mutations disrupt the proton potential for flagellar rotation and the electron leakage increases the generation of ROS, including the superoxide anion, and affects oxidative stress in C. jejuni (Flint et al., 2014).

\section{Peroxide Stress Defense}

Catalase, which decomposes $\mathrm{H}_{2} \mathrm{O}_{2}$ to $\mathrm{H}_{2} \mathrm{O}$ and $\mathrm{O}_{2}$, plays an important role in oxidative defense mechanism (Imlay, 2008). The katA gene is the sole catalase gene present in C. jejuni. Studies using a kat $A$ knockout mutant have revealed the primary role of katA in scavenging $\mathrm{H}_{2} \mathrm{O}_{2}$ under oxidative stress and in the survival of C. jejuni within macrophages (Grant and Park, 1995; Day et al., 2000). The heme-trafficking protein Cj1386, which is located downstream of $k a t A$, is involved in the full catalase activity and contributes to $C$. jejuni colonization of chicken intestines (Flint et al., 2012). C. jejuni has three different antioxidant enzymes in the peroxiredoxin family, including alkyl hydroperoxide reductase $(\mathrm{AhpC})$, and two putative peroxidases [i.e., thiol peroxidase ( $\mathrm{Tpx}$ ) and bacterioferritin comigratory protein (Bcp)] (Baillon et al., 1999; Parkhill et al., 2000). In Salmonella enterica, alkyl hydroperoxide reductase consists of two subunit AhpC and AhpF; the former is a peroxide reducing part and the latter is a flavoprotein that uses $\mathrm{NAD}(\mathrm{P}) \mathrm{H}$ as an electron donor to transfer electrons to AhpC (Jacobson et al., 1989; Storz et al., 1989). Unlike Salmonella and E. coli, C. jejuni possesses only $a h p C$ and lacks an $a h p F$ homolog in the genome (Baillon et al., 1999). AhpC expression is controlled by iron concentrations at the transcriptional level, and iron restriction increases the AhpC transcription level (Baillon et al., 1999). An $a h p C$ knockout mutant is highly sensitive to cumene hydroperoxide (an organic peroxide), but not to $\mathrm{H}_{2} \mathrm{O}_{2}$ (Baillon et al., 1999), possibly because C. jejuni AhpC would scavenge endogenous $\mathrm{H}_{2} \mathrm{O}_{2}$ at physiological concentrations as E. coli AhpC does (Seaver and Imlay, 2001). Two Tpxs (i.e., Tpx and $\mathrm{Bcp}$ ) are commonly involved in $\mathrm{H}_{2} \mathrm{O}_{2}$ defense, and $\mathrm{Bcp}$ reduces also organic peroxides, such as cumene hydroperoxide and tert-butyl hydroperoxide (Atack et al., 2008). Cytochrome $c$ peroxidase (CCP) is a periplasmic protein that reduces $\mathrm{H}_{2} \mathrm{O}_{2}$ to water. C. jejuni possesses two putative CCP genes; docA and Cjj0382 (Parkhill et al., 2000; Hendrixson and DiRita, 2004).
Even though the two genes exhibit the common characteristics of CCP, such as heme-binding periplasmic proteins, none of them contribute to $\mathrm{H}_{2} \mathrm{O}_{2}$ resistance in C. jejuni 81-176 (BinghamRamos and Hendrixson, 2008). In C. jejuni NCTC 11168, however, a mutation of Cj0358, which is Cjj0382 in C. jejuni 81-176, is associated with $\mathrm{H}_{2} \mathrm{O}_{2}$ resistance (Flint et al., 2014), suggesting that Cj0358 (Cjj0382) would affect oxidative stress defense strain-dependently. Also, the autoinducer 2-depdendent quorum sensing affects oxidative stress depending on the strain. A luxS mutant in C. jejuni NCTC 11168 exhibits comparable resistance to oxidative stress to the wild type (Elvers and Park, 2002); however, a luxS mutation in C. jejuni 81-176 increases the sensitivity to peroxides $\left(\mathrm{H}_{2} \mathrm{O}_{2}\right.$ and cumene hydroperoxide; $\mathrm{He}$ et al., 2008). The rubredoxin oxidoreductase/rubrerythrin chimeric protein $\mathrm{Rrc}$ is a non-heme iron protein, interacts with exogenous and endogenous $\mathrm{H}_{2} \mathrm{O}_{2}$, and confers resistance to menadione (i.e., superoxide) and $\mathrm{H}_{2} \mathrm{O}_{2}$ (Yamasaki et al., 2004; Flint et al., 2014).

Complementary mechanisms have been reported to protect C. jejuni from oxidative stress by scavenging free intracellular irons associated with ROS generation or by repairing cellular damages caused by ROS. The E. coli Dps (DNA binding protein from starved cells) is known to protect DNA by sequestrating free $\mathrm{Fe}^{2+}$ and by reducing the formation of ROS (Zhao et al., 2002). In C. jejuni, similarly, Dps captures free $\mathrm{Fe}^{2+}$ and confers resistance to $\mathrm{H}_{2} \mathrm{O}_{2}$ (Ishikawa et al., 2003). Upon activation by $\mathrm{Fe}^{2+}$ or $\mathrm{H}_{2} \mathrm{O}_{2}$, Dps binds to and protects DNA from damages from hydroxyl radicals (Huergo et al., 2013). Methionine sulphoxide reductases (MsrA and $\mathrm{MsrB}$ ) reduces oxidized methionine (i.e., methionine sulphoxide [Met-SO]) to methionine and restores methionine function in protein synthesis (Ezraty et al., 2005). Mutations of $m s r A$ and $m s r B$, especially an $m s r A / B$ double mutation, sensitize $C$. jejuni to peroxide and superoxide stress and nitrosative stress as well (Atack and Kelly, 2008). CmeG is a multidrug efflux pump that belongs to the major facilitator superfamily (MFS), playing a role in antimicrobial resistance in C. jejuni. Particularly, $\mathrm{CmeG}$ overexpression significantly increases $C$. jejuni resistance to fluoroquinolone antibiotics. In addition to the role in antibiotic resistance, interestingly, $\mathrm{CmeG}$ significantly affects $C$. jejuni susceptibility to $\mathrm{H}_{2} \mathrm{O}_{2}$ (Jeon et al., 2011).

Although a number of genes and proteins have been reported to contribute to oxidative stress defense in C. jejuni (Table 1), a recent extensive mutagenesis and colonization study done by Flint et al. (2014) revealed that $a h p C$, katA, and $\operatorname{sodB}$ play the primary role in the oxidative stress defense of $C$. jejuni.

\section{Oxidative Stress and C. jejuni's Stress Response}

Bacteria coordinate complex regulatory systems to achieve effective response to different stress conditions by removing the sources of stress and by repairing cellular damages resulting from the stress (Kültz, 2005; Guo and Gross, 2014). Many different stress situations activate general stress response to cross-protect bacteria from various stress conditions; "cross-protection" means 
TABLE 1 | Proteins associated with oxidative stress defense in C. jejuni.

\begin{tabular}{|c|c|c|c|}
\hline Name & Functions & Susceptibility increase by mutation & Reference \\
\hline Superoxide dismutase (SodB) & Dismutation of superoxide & $\begin{array}{l}\text { Superoxide (MND)* } \\
\text { Organic peroxide }(\mathrm{CHP})^{* *} \\
\mathrm{H}_{2} \mathrm{O}_{2}\end{array}$ & $\begin{array}{l}\text { Palyada et al. (2009), Flint } \\
\text { et al. (2014) }\end{array}$ \\
\hline Cj1371 & $\begin{array}{l}\text { Homolog of Shigella flexneri } \\
\text { VacJ }\end{array}$ & Superoxide $(\mathrm{PQ})^{* * *}$ & Garénaux et al. (2008a) \\
\hline $\begin{array}{l}\text { Methionine sulphoxide reductases } \\
\text { (MsrA/B) }\end{array}$ & Repair of oxidized methionine & $\begin{array}{l}\mathrm{H}_{2} \mathrm{O}_{2} \\
\text { Organic peroxide (CHP) } \\
\text { Superoxide (PQ) } \\
\text { Nitrosative stress }\end{array}$ & Atack and Kelly (2008) \\
\hline $\begin{array}{l}\text { Rubredoxin oxidoreductase } \\
\text { /rubrerythrin-like protein (Rrc) }\end{array}$ & Unknown & $\begin{array}{l}\mathrm{H}_{2} \mathrm{O}_{2} \\
\text { Superoxide (MND) }\end{array}$ & $\begin{array}{l}\text { Yamasaki et al. (2004), } \\
\text { Flint et al. (2014) }\end{array}$ \\
\hline Catalase & Decomposition of $\mathrm{H}_{2} \mathrm{O}_{2}$ & $\mathrm{H}_{2} \mathrm{O}_{2}$ & Grant and Park (1995) \\
\hline Cj1386 & Heme trafficking to KatA & $\mathrm{H}_{2} \mathrm{O}_{2}$ & Flint et al. (2012) \\
\hline Alkyl hydroperoxide reductase (AhpC) & $\begin{array}{l}\text { Reduction of alkyl peroxides } \\
\text { Scavenger of endogenous } \\
\mathrm{H}_{2} \mathrm{O}_{2}\end{array}$ & Organic peroxide (CHP) & Baillon et al. (1999) \\
\hline $\begin{array}{l}\text { Thiol peroxidase (Tpx) and Bacterioferritin } \\
\text { comigratory protein (Bcp) }\end{array}$ & $\begin{array}{l}\text { Scavenger of } \mathrm{H}_{2} \mathrm{O}_{2} \\
\text { Reduction of peroxides }\end{array}$ & $\begin{array}{l}\text { In a tpx/bcp double mutant } \\
\mathrm{H}_{2} \mathrm{O}_{2} \\
\text { Organic peroxide (CHP) } \\
\text { Superoxide (PQ) } \\
\text { Nitrosative stress }\end{array}$ & Atack et al. (2008) \\
\hline Cytochrome $c$ peroxidases (CCPs) & Reduction of $\mathrm{H}_{2} \mathrm{O}_{2}$ & $\begin{array}{l}\text { None in } \mathrm{C} \text {. jejuni 81-176 } \\
\mathrm{H}_{2} \mathrm{O}_{2} \text { in a Cj0358 mutant of } C \text {. jejuni } \\
\text { NCTC } 11168\end{array}$ & $\begin{array}{l}\text { Bingham-Ramos and } \\
\text { Hendrixson (2008), Flint et al. } \\
\text { (2014) }\end{array}$ \\
\hline S-ribosylhomocysteinase (LuxS) & Synthesis of autoinducer-2 & $\begin{array}{l}\text { None in C. jejuni NCTC } 11168 \\
\mathrm{H}_{2} \mathrm{O}_{2} \text { and organic peroxide }(\mathrm{CHP}) \text { in } \\
\text { C. jejuni } 81-176\end{array}$ & $\begin{array}{l}\text { Elvers and Park (2002), } \\
\text { He et al. (2008) }\end{array}$ \\
\hline $\begin{array}{l}\text { DNA binding protein from starved cells } \\
\text { (Dps) }\end{array}$ & $\begin{array}{l}\text { Sequestration of free } \mathrm{Fe}^{2+} \\
\text { Protection of DNA from } \\
\text { oxidative damage }\end{array}$ & $\mathrm{H}_{2} \mathrm{O}_{2}$ & $\begin{array}{l}\text { Ishikawa et al. (2003), Huergo } \\
\text { et al. (2013) }\end{array}$ \\
\hline CmeG, a multidrug efflux transporter & Excretion of toxic compounds & $\mathrm{H}_{2} \mathrm{O}_{2}$ & Jeon et al. (2011) \\
\hline
\end{tabular}

*MND, menadione; **CHP, cumene hydroperoxide; ***PQ, paraquat.

that cells exposed to one stress also become resistant to other stress (Hengge-Aronis, 2002; Capozzi et al., 2009; Wesche et al., 2009). In addition to the primary role of ROS detoxification, oxidative stress defense is also associated with other stress response mechanisms. In E. coli, oxidative stress is involved in bacterial response to a variety of stress conditions, such as heat, salinity, heavy metals, and lactic acid bacteria (Imlay, 2015). Oxidative stress is associated even with antimicrobial killing of pathogens (Kohanski et al., 2007). Treatment of E. coli and $S$. aureus with bactericidal antibiotics stimulates bacterial respiration, resulting in the depletion of NADH and the generation of toxic ROS (Kohanski et al., 2007). The implication of oxidative stress in antimicrobial lethality is under debate (Imlay, 2015), because antimicrobial activity still persists in the absence of oxygen (Liu and Imlay, 2013) and this antimicrobial mechanism appears to be influenced by unique bacterial metabolisms, particularly tricarboxylic acid pathway (Feld et al., 2012). Nevertheless, antimicrobial killing of $C$. jejuni is affected by oxidative stress. Mutations of kat $A$ and $\operatorname{sodB}$ affect the bacterial lethality of ciprofloxacin and rifampicin with a reduction in the minimal inhibitory concentrations (MICs) by about twofold (Hwang et al., 2013). As discussed below, oxidative stress also affects $C$. jejuni response to different stress conditions that this foodborne pathogen may encounter during its transmission to humans via food.

\section{Temperature Stress}

Most foodborne pathogens are originated from the gastrointestinal tracts of animals and usually grow optimally at temperatures close to the body temperatures of host animals. Foodborne pathogens may experience dramatic temperature changes during food processing, storage, and preparation (Capozzi et al., 2009), and resist the stress of temperature changes by producing heat- and cold-shock proteins (Becker and Craig, 1994; Wouters et al., 2000; Beales, 2004). Interestingly, oxidative stress is related to $C$. jejuni response to temperature stress. The catalase activity increases in $C$. jejuni in proportion to temperatures (Hazeleger et al., 1998), but C. jejuni is more susceptible to oxidative stress at high temperature (i.e., $42^{\circ} \mathrm{C}$ ) than low temperatures (i.e., $4^{\circ} \mathrm{C}$ ), suggesting that temperature affects oxidative stress resistance in C. jejuni (Garénaux et al., 2008b). Exposure to cold-shock increases the expression of sodB and Cj0358 (a CCP; Stintzi and Whitworth, 2003), and a sodB mutation makes $C$. jejuni and C. coli more susceptible to freeze-thaw stress (Stead and Park, 2000; Garénaux et al., 2009), 
suggesting that oxidative stress influences $C$. jejuni ability to survive under freeze-thaw conditions.

\section{Acid Stress}

Since low $\mathrm{pH}$ conditions are frequently adopted to food preservation, foodborne pathogens may encounter acid stress in foods (Hill et al., 1995). In addition, passage through the stomach would be the most demanding challenge for foodborne pathogens during infection (Chowdhury et al., 1996). In E. coli O157:H7, acid exposure alters the transcriptional level of oxidative stress genes, including $o x y R$ and soxS, which are key regulators of oxidative stress defense (Allen et al., 2008). Dps is an ironsequestration ferritin protein and contributes to both acid and oxidative stress defense by protecting E. coli O157:H7 from DNA damage (Choi et al., 2000; Jeong et al., 2008). In C. jejuni, similarly, the expression of oxidative stress defense genes, such as $d p s, \operatorname{sod} B, \operatorname{tr} x B$, and $a h p C$, is increased by exposure to $\mathrm{HCl}$ or acetic acid (Birk et al., 2012). Pre-exposure of C. jejuni to aerobic culture increases bacterial survival under acid stress, suggesting that oxidative stress is linked to acid stress response (Murphy et al., 2003).

\section{Osmotic Stress}

The use of osmolytes as food preservatives decreases water activity and contributes to the control of microbial growth in food (Beales, 2004). Under high osmotic pressure, cells activate defense systems to prevent shrinkage and plasmolysis (Beales, 2004; Chung et al., 2006). In Bacillus cereus, pre-exposure to $1 \% \mathrm{NaCl}$ increases resistance to $\mathrm{H}_{2} \mathrm{O}_{2}$ (Browne and Dowds, 2001). Exposure of $B$. cereus to both mild $(2.5 \% \mathrm{NaCl})$ and severe $(5 \% \mathrm{NaCl})$ salt stress also increases expression of oxidative stress defense genes, such as $a h p C$, katA, and katE, along with genes associated with iron homeostatis, such as ferrochelatase (den Besten et al., 2009). Similarly, exposure of C. jejuni to $1 \%$ $\mathrm{NaCl}$ up-regulates oxidative stress genes, such as kat $A$ and $\operatorname{sodB}$, over an extended exposure time from $15 \mathrm{~min}$ to $6 \mathrm{~h}$, suggesting oxidative stress defense is involved in osmotic stress response (Cameron et al., 2012).

\section{Nutrient Starvation}

Nutrient starvation in foodborne pathogens can occur at any time during transmission to humans, such as growth on the surface of food processing equipment. Starvation stress induces cross-protection against heat, oxidative, and osmotic stress in E. coli (Jenkins et al., 1988, 1990). Enterococcus faecalis develops a multi-resistance state against heat, $\mathrm{H}_{2} \mathrm{O}_{2}$, acid, and ethanol after exposure to carbohydratelimited environments (Giard et al., 1996). In stationary phase (starvation-like condition), C. jejuni undergoes a physiological switch from acetate production to acetate uptake, and the oxidative stress genes, such as $p e r R, \operatorname{ahpC}, \operatorname{sodB}$, and $t p x$, are up-regulated during the metabolic switch (Wright et al., 2009).

As described above, oxidative stress is associated with C. jejuni's response to various stresses; however, it remains unexplained how oxidative stress is related to different stress conditions in C. jejuni. Similar to the mechanism for antibiotic killings via oxidative stress, presumably, exposure to stress may affect metabolisms and electron transport systems, consequently resulting in ROS generation. Stress conditions may compromise C. jejuni's capability to maintain the homeostasis of ROS, and C. jejuni would further require the function of oxidative stress defense systems to cope with the instability in ROS homeostasis under the stress conditions.

\section{Effect of Oxidative Stress on Survival Mechanisms in C. jejuni}

As a common stress response mechanism, oxidative stress defense also plays a role in the survival mechanisms of C. jejuni, such as aerotolerance, biofilm formation, and induction of a viable-but-non-culturable (VBNC) state. Biofilm formation is one of extensively studied survival mechanisms in pathogenic bacteria in stress environments (Parsek and Singh, 2003). Biofilm formation on food processing equipment is a major concern to food industry, since biofilms may persistently release microorganisms and act as a source of microbial contamination (Hall-Stoodley and Stoodley, 2005). Bacteria in biofilms are physiologically different from cells in a planktonic state and highly resistant to chemical disinfectants and antibiotics (Fux et al., 2005). When residing in biofilms, C. jejuni easily acquires antibiotic resistance genes because DNA is a major structural material of biofilms and C. jejuni is naturally competent in DNA uptake (Bae et al., 2014). Oxidative stress is associated with biofilm formation in foodborne pathogens. According to a proteomic analysis of the protein expression profiles in E. coli O157:H7 biofilms, the protein expression levels of Tpx and SodC increase in biofilms, and $t p x$, and sodC mutants exhibit a significant defect in biofilm formation (Kim et al., 2006). Similarly, the expression of oxidative stress resistance proteins AhpC and Tpx also increases in C. jejuni biofilms (Kalmokoff et al., 2006). In C. jejuni, inactivation of $a h p C$ increases the accumulation of the total ROS and lipid peroxides, and significantly enhances biofilm formation (Oh and Jeon, 2014). Antioxidant treatment reduces the enhanced biofilm formation in the $a h p C$ mutant to the wild-type level (Oh and Jeon, 2014), suggesting that oxidative stress is one of signals that induce biofilm formation in C. jejuni. C. jejuni is microaerophilic; however, C. jejuni forms biofilms more vigorously in oxygenrich (i.e., aerobic) conditions than in oxygen-limited (i.e., microaerobic) conditions (Reuter et al., 2010). This would be because increased oxidative stress under aerobic conditions may enhance biofilm formation. We also observed that antioxidant treatment decreased the levels of biofilm formation under aerobic conditions (unpublished data).

Oxidative stress also impacts the entry of $C$. jejuni into a VBNC state. Bacteria in a VBNC state are alive but not culturable by traditional microbiological methods, and removal of inducing stress resuscitates VBNC cells and allows them to grow in laboratory conditions (Oliver, 2010). VBNC cells are characterized by the typical size reduction and coccoid cellular morphology (Oliver, 2010). The length of an individual C. jejuni 
cell is $6 \mu \mathrm{m}$; however, the average length of $C$. jejuni VBNC cell is approximately $1.19 \mu \mathrm{m}$ (Thomas et al., 2002). Several factors have been reported to induce a VBNC state in C. jejuni, including as temperature, starvation, formic acid, and aerobic conditions (Kassem et al., 2013). Our recent study reported significant morphological changes in C. jejuni from rod-spiral to coccoid forms after exposure to oxygen-rich conditions (Kim et al., 2015), and our further characterization demonstrated that increased oxidative stress induces the formation of VBNC C. jejuni under aerobic conditions (Oh et al., 2015). Oxidative stress also affects the induction of a VBNC state in Vibrio vulnificus. An oxyR mutant of $V$. vulnificus that is defective in catalase activity easily enters a VBNC state compared to the parent strain (Kong et al., 2004). Supplementation of $\mathrm{H}_{2} \mathrm{O}_{2}$-degrading enzyme and ROS scavenging compounds, such as catalase and sodium pyruvate, enhances resuscitation of E. coli $\mathrm{O} 157$ and $V$. vulnificus from a non-culturable state (Mizunoe et al., 1999; Bogosian et al., 2000), indicating alleviation of oxidative stress promotes bacterial resuscitation from a VBNC state.

Aerotolerance would be the survival mechanism that is most closely connected to oxidative stress. Although obligate anaerobes and microaerohiles reside in habitats under oxygenlimited conditions to avoid oxidative stress, the oxygen-sensitive bacteria still possess conserved oxidative stress resistance systems to survive in oxygen-rich conditions (Chiang and Schellhorn, 2012). Several studies have demonstrated that genes of oxidative stress defense contribute to aerotolerance in C. jejuni. Mutations of $a h p C$ and its upstream gene $f d x A$ significantly decreases aerotolerance in C. jejuni (Baillon et al., 1999; van Vliet et al., 2001), and two thiol peroxidases, Tpx and Bcp, contribute to C. jejuni's aerotolerance (Atack et al., 2008). More ROS accumulates under aerobic conditions than microaerobic conditions with increased oxidation of proteins and lipids (Oh et al., 2015). Although kat $A, \operatorname{sodB}$, and $a h p C$ are key enzymes of ROS detoxification, $a h p C$ plays a more important role in $C$. jejuni survival under oxygen-rich conditions than kat $A$ and $\operatorname{sodB}(\mathrm{Oh}$ et al., 2015).

\section{Regulation of Oxidative Stress Defense}

\section{Oxidative Stress Defense Regulators in Other Bacteria}

Oxidative stress defense is controlled by complicated regulatory systems. Most well-characterized regulatory systems of oxidative stress defense would be SoxRS and OxyR, which are dedicated to the regulation of superoxide and peroxide defense, respectively, in E. coli and Salmonella (Imlay, 2008). SoxR (superoxide response regulator) was first identified as a genetic locus that positively regulates protein expression after exposure to superoxide-generating agents, such as paraquat (Greenberg et al., 1990; Tsaneva and Weiss, 1990). Redox-cycling drugs generating the superoxide anion directly activate SoxR (Gu and Imlay, 2011), and the activated SoxR stimulates the expression of SoxS, which subsequently induces oxidative stress defense genes (Pomposiello et al., 2001). OxyR is activated by $\mathrm{H}_{2} \mathrm{O}_{2}$ through the oxidation of two cysteine residues (i.e., Cys 199 and Cys 208) and the formation of a disulfide bond (Zheng et al., 1998; Imlay, 2008). Oxidized OxyR binds to promoters co-operatively with the RNA polymerase in E. coli (Tao et al., 1993), and positively regulates a group of peroxide stress defense genes, such as ahpCF, dps, and $k a t G$, whose expression is also induced by $\mathrm{H}_{2} \mathrm{O}_{2}$ (Zheng et al., 2001). PerR (peroxide resistance regulator) is the major regulator of peroxide stress defense in Gram-positive bacteria, such as Bacillus subtilis, Staphylococcus aureus, and Streptococcus pyogenes, and in some Gram-negative bacteria, including C. jejuni and Helicobacter hepaticus (van Vliet et al., 1999; Mongkolsuk and Helmann, 2002; Belzer et al., 2011). As a member of Fur (ferric uptake regulator) family of metallo-regulators, B. subtilis PerR senses the intracellular Fe/Mn ratio and requires metal ions, including $\mathrm{Zn}^{2+}$ as a structural ion, and $\mathrm{Mn}^{2+}$ and $\mathrm{Fe}^{2+}$ as regulatory ions (Helmann, 2014). While $\mathrm{Fe}^{2+}$ mediates PerR regulation of peroxide defense genes, such as katA, ahpCF, and $m r g A$ (a homolog of $d p s$ ), the negative auto-regulation of perR involves $\mathrm{Mn}^{2+}$ in B. subtilis (Fuangthong et al., 2002). Although $B$. subtilis PerR regulates peroxide defense genes, perR transcription is not affected by $\mathrm{H}_{2} \mathrm{O}_{2}$ (Fuangthong et al., 2002). Instead, conformational changes in the PerR protein by $\mathrm{H}_{2} \mathrm{O}_{2}$ stress contribute to the regulatory function of PerR. Oxidation of one of two histidine residues (i.e., $\mathrm{H} 37$ and $\mathrm{H} 91$ ) by $\mathrm{H}_{2} \mathrm{O}_{2}$ in B. subtilis PerR results in the dissociation of $\mathrm{Fe}^{2+}$ from PerR, and the demetallated PerR cannot bind to DNA, and this conformational changes in PerR induce gene expression (Lee and Helmann, 2006).

\section{Oxidative Stress Defense Regulators in C. jejuni}

Unlike other Gram-negative foodborne pathogenic bacteria, such as E. coli and Salmonella enterica, the soxRS and oxyR homologs are not found in the C. jejuni genome (Parkhill et al., 2000). Instead, PerR and CosR have been characterized relatively well in the regulation of oxidative stress defense in C. jejuni (Figure 1).

(1) PerR: The C. jejuni genome contains two genes encoding Fur homologs. Whereas Fur regulates iron uptake genes (van Vliet et al., 1998; Palyada et al., 2004; Holmes et al., 2005), another Fur homolog, PerR, is involved in the regulation of peroxide stress resistance (van Vliet et al., 1999). As PerR is rarely present in Gram-negative bacteria, C. jejuni is the first Gram-negative bacterium that has been shown to possess PerR (van Vliet et al., 1999). Similar to the regulatory patterns of B. subtilis PerR (Bsat et al., 1998), a perR mutation significantly increases the expression of antioxidant proteins, KatA and AhpC, rendering the $C$. jejuni perR mutant hyper-resistant to peroxides, such as $\mathrm{H}_{2} \mathrm{O}_{2}$ and cumene hydroperoxide (van Vliet et al., 1999). A microarray analysis done by Palyada et al. (2009) further demonstrated that PerR directly or indirectly regulates at least 104 genes, including those of oxidative stress defense and motility. Although C. jejuni PerR shares 32\% identity to B. subtilis PerR (Kim et al., 2011) and shows functional similarities in peroxide defense regulation, $C$. jejuni PerR exhibits some unique differences from B. subtilis PerR. The transcription of perR is driven by two consecutive, overlapping promoters, and the PerR box overlaps with the entire -35 box of the upstream promoter 


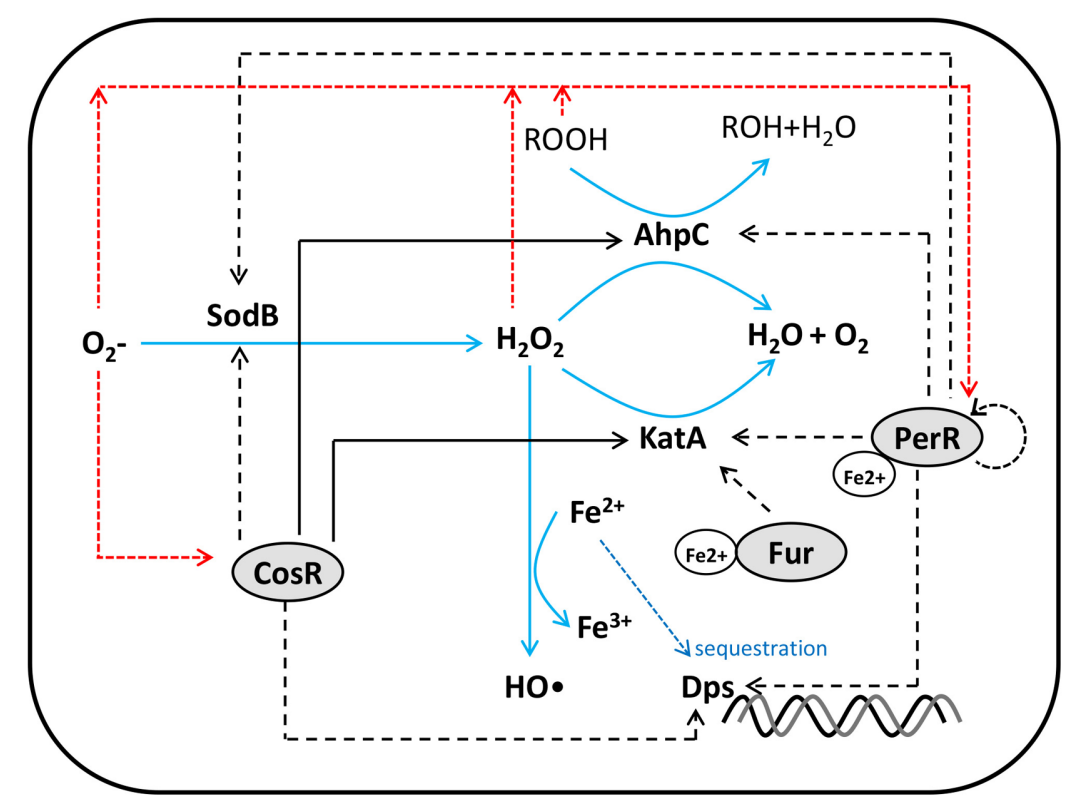

FIGURE 1 | Schematic diagram for Campylobacter oxidative stress regulator (CosR) (Hwang et al., 2011b, 2012), ferric uptake regulator (Fur) (Butcher et al., 2012), and peroxide resistance regulator (PerR) (van Vliet et al., 1999; Palyada et al., 2009; Kim et al., 2011, 2015) regulation of oxidative stress resistance in C. jejuni. Positive and negative regulations are indicated by black solid and dotted lines, respectively. Red dotted lines show transcriptional or translational down regulation by reactive oxygen species (ROS) and a part of the downstream promoter (Kim et al., 2011). Similar to B. subtilis, perR transcription is negatively auto-regulated in C. jejuni; thus, PerR binding to the perR promoter interferes with perR transcription (Kim et al., 2011). Whereas perR autoregulation involves manganese in $B$. subtilis (Fuangthong et al., 2002), perR autoregulation in C. jejuni is mediated by iron, not by manganese (Kim et al., 2011).

Recently, we showed oxidative stress defense plays a role in C. jejuni survival under aerobic conditions (Oh et al., 2015). Aerobic culture of C. jejuni significantly increases the transcriptional levels of $\operatorname{ahpC}$, katA, and $\operatorname{sodB}$ by ROS accumulation, and a perR mutation abrogated the transcriptional induction of the three antioxidant genes by oxidants, demonstrating PerR modulates transcriptional changes in response to increased oxidative stress under aerobic conditions in C. jejuni (Kim et al., 2015). Interestingly, PerR binds to the $\operatorname{sod} B$ promoter and negatively regulates the transcription of $\operatorname{sod} B$, the most representative gene in superoxide defense (Kim et al., 2015). These findings suggest that PerR regulates both peroxide and superoxide defense in C. jejuni. The possibility of PerR regulation of $\operatorname{sod} B$ has also been suggested in a review article of van Vliet et al. (2002) based on a sequence analysis by using a putative PerR binding sequence in Gram-positive bacteria in spite of the issue in sequence similarities between PerR and Fur boxes. Unlike E. coli and Salmonella that regulate oxidative stress defense with stress-specific regulators, such as OxyR and SoxRS, C. jejuni PerR regulates the transcription of both peroxide and superoxide defense genes.

As forementioned, PerR regulation of oxidative stress defense genes in B. subtilis is mediated by conformational changes in the
PerR protein in response to oxidative stress (Lee and Helmann, 2006). The same mechanism is likely to be present in C. jejuni, because two histidine residues (i.e., H37 and H91) are conserved in C. jejuni PerR (Kim et al., 2011). In addition, PerR regulation of oxidative stress is also mediated at the perR transcriptional level; both peroxide and superoxide reduce the level of perR transcription regardless of the presence and absence of iron (Kim et al., 2015). Taken together, exposure to oxygen-rich conditions, such as aerobic conditions, increases the intracellular ROS levels in C. jejuni, which subsequently decreases perR transcription, resulting in the derepression of oxidative stress defense genes.

(2) Fur: Fur is a key transcriptional regulator in the control of iron homeostasis in C. jejuni (van Vliet et al., 1998). In addition, its contribution to oxidative stress regulation has been suggested in C. jejuni. Catalase activity increases by a perR mutation twofold less in iron-rich conditions than iron-limited conditions, and a perR/fur double mutation results in comparable levels of catalase activities irrespective of iron, meaning that PerR and Fur co-regulates peroxide resistance (van Vliet et al., 1999). A recent chromatin immunoprecipitation and microarray analysis of Butcher et al. (2012) shows that holo-Fur (i.e., ironbound Fur) represses katA and activates $r r c$, whereas apo-Fur represses rrc. Similarities in the binding sites of PerR and Fur have been an issue in the determination of the regulon of each regulator (van Vliet et al., 2002). In fact, the PerR box is more similar to the holo-Fur box for repression than the Fur box for activation in C. jejuni based on two recent studies (Kim et al., 2011; Butcher et al., 2012). Given the repression of katA by both PerR and holo-Fur and their binding site similarities, 
it is still not clear how the two iron-associated transcriptional regulators coordinate katA expression in C. jejuni. Nevertheless, PerR appears to play a more important role than Fur, because a perR mutation results in more significant increase in catalase activity and $\mathrm{H}_{2} \mathrm{O}_{2}$ resistance than a fur mutation does (van Vliet et al., 1998).

(3) CosR: CosR (Campylobacter oxidative stress regulator) is an OmpR-type essential response regulator that plays an important role in the control of oxidative stress resistance in C. jejuni (Hwang et al., 2011b, 2012). The C. jejuni genome contains six histidine kinases, 11 response regulators, and an hybrid of histidine kinase and response regulator (CheA; Parkhill et al., 2000; Marchant et al., 2002). In an extensive mutagenesis study, Raphael et al. (2005) endeavored to knock out 11 putative two-component response regulators, but $\cos R(C j 0355 c)$, and $c p r R$ (Cj1227c) mutants could not be generated, suggesting that these two genes are essential in C. jejuni. Garénaux et al. (2008a) reported that exposure of $C$. jejuni to paraquat, a superoxide generator, reduces the protein level of CosR $(\mathrm{Cj} 0355 \mathrm{c})$ in a 2DGE analysis, suggesting a potential role of CosR in oxidative stress defense. In the two studies above, the essentiality of $\cos R$ was an obstacle to functional characterization of CosR, because it is not possible to generate its knock-out mutant. Thus, the function of CosR has been characterized in an alternative way by using antisense-mediated gene knockdown (Hwang et al., 2011b), which was technically established in C. jejuni first by Jeon and Zhang (2009). A 2DGE analysis of protein expression profiles under CosR knockdown and overexpression conditions identified 32 proteins whose expression is significantly affected by CosR, revealing CosR regulates positively AhpC, and negatively SodB, Dps, and Rrc (Hwang et al., 2011b). A further characterization of CosR regulon by using a DNA microarray exhibited CosR positively regulates kat $A$ expression, and CosR knockdown and overexpression affect catalase activity (Hwang et al., 2012). CosR regulation of oxidative stress defense genes (i.e., $a h p C, d p s, k a t A, \operatorname{sodB}$ ) is direct based on the results of electrophoretic mobility shift assays and DNase I footprinting assays (Hwang et al., 2011b, 2012). Additionally, CosR negatively regulates the $c m e A B C$ operon encoding the major multidrug efflux pump CmeABC in C. jejuni, and several genes of bacterial motility, such as $f l g D$, flgE, $f l g L$, and $f l i K$, suggesting the pleiotropic regulation of CosR in C. jejuni (Hwang et al., 2012). The CosR protein level is reduced by paraquat, but not by $\mathrm{H}_{2} \mathrm{O}_{2}$ (Hwang et al., 2011b), indicating that CosR specifically senses superoxide stress, although CosR regulates both peroxide and superoxide resistance genes. Since superoxide is the first line of toxic by-product from oxygen reduction cycle, superoxide sensing would probably be more efficient than peroxide sensing in C. jejuni response to oxidative stress. CosR also negatively regulates expression of LuxS (Hwang et al., 2011b), which affects oxidative stress resistance in a strain-dependent manner (see, Peroxide Stress Defense section above).

Campylobacter oxidative stress regulator homologs are predominantly found in bacteria that belong to $\varepsilon$-Proteobacteria, such as Campylobacter, Helicobacter, Arcobacter, and Wolinella (Hwang et al., 2011b). CosR appears to be an orphan response regulator, because a potential sensor kinase does not exist nearby the $\cos R$ gene in C. jejuni (Hwang et al., 2011b) as well as in other thermotolerant Campylobacter sp., such as C. coli and C. lari (Hwang et al., 2014). Interestingly, however, the sensor kinase CosS is present in non-theremotolerant Campylobacter sp., such as C. fetus, C. concisus, C. curvus, and C. hominis, and also in other members of $\varepsilon$-Proteobacteria, including Wolinella and Arcobacter (Hwang et al., 2014). Based on the inability to obtain a $\cos R$ knockout mutant in $C$. fetus, $\cos R$ appears to be essential in C. fetus (Hwang et al., 2014). A mutation of the sensor kinase cosS slightly reduces aerotolerance in C. fetus, but does not affect oxidative stress resistance (Hwang et al., 2014). Despite high similarities in the amino acid sequence in CosR homologs in thermotolerant and non-thermotolerant Campylobacter sp., the histidine kinase CosS in non-thermotolerant C. fetus does not mediate phosphotransfer to $C$. jejuni CosR, suggesting that CosR functions differentially between therotolerant and non-thermontolerant Campylobacter species (Hwang et al., 2014).

(4) Other regulators: In addition to the regulators mentioned above, several other regulators have been reported to affect oxidative stress defense in Campylobacter. The CprRS twocomponent system consists of an essential response regulator (CprR) and the sensor kinase CprS (Svensson et al., 2009). Due to the indispensability of CprR in C. jejuni survival, the cprR gene cannot be knocked out, but a cprS mutation, which is not lethal to C. jejuni, results in decrease in SodB, Rrc, LuxS, and CosR expression and increase in $\mathrm{AhpC}$ and KatA expression in a 2DGE analysis, also slightly increasing sensitivity to both peroxide and superoxide stress (Svensson et al., 2009). Further characterization of $c p r S$ revealed that CprRS contributes to the regulation of genes associated with bacterial envelope, such as $h t r A, p e b 4$, lepP, lspA, and gne (Svensson et al., 2015). Cj1556 is a MarR family transcriptional regulator and positively regulates peroxide stress defense genes, such as perR, katA, and $a h p C$, whereas $\operatorname{sodB}$ is negatively regulated by C 1556 (Gundogdu et al., 2011). A Cj1556 mutation reduces $C$. jejuni capability to resist oxidative, aerobic, and heat stress and to survive in human intestinal epithelial cells and murine macrophages (Gundogdu et al., 2011). Cj1103 is an ortholog of the E. coli global posttranscriptional regulator CsrA (carbon starvation regulator) and functionally complements a $\operatorname{csr} A$ mutation in $E$. coli in the regulation of biofilm formation and motility (Fields and Thompson, 2012). Inactivation of $c s r A$ increases sensitivity to hydrogen peroxide and aerobic stress (Fields and Thompson, 2008). C. jejuni harbors only three sigma factors, including $\operatorname{RpoD}\left(\sigma^{70}\right)$, RpoN $\left(\sigma^{54}\right)$, and FliA $\left(\sigma^{28}\right)$, and lacks stress-related sigma factors found in other bacteria (e.g., RpoS; Parkhill et al., 2000). RpoD and FliA are sigma factors that are dedicated to the transcription of housekeeping and flagella biosynthesis genes, respectively, and RpoN is known to be involved in flagella biosynthesis and bacterial motility in C. jejuni (Hendrixson et al., 2001). Although RpoN is not a regulator, RpoN has been shown to affect oxidative stress response in C. jejuni (Hwang et al., 2011a).

In summary, oxidative stress resistance affects: (1) bacterial response to various stress conditions that $C$. jejuni may encounter during foodborne transmission to humans, and 
(2) critical survival mechanisms, such as aerotolerance, biofilm and VBNC formation. C. jejuni's resistance to and survival in stress conditions that are associated with oxidative stress defense may eventually increase the possibility of $C$. jejuni transmission to humans via food, resulting in food safety problems. Additionally, studies thus far have demonstrated that oxidative stress response in C. jejuni is controlled by many different regulatory mechanisms that are distinctly different

\section{References}

Ahmed, N. M., Conner, D. E., and Huffman, D. L. (1995). Heat-resistance of Escherichia coli O157:H7 in meat and poultry as affected by product composition. J. Food Sci. 60, 606-610. doi: 10.1111/j.1365-2621.1995.tb0 9838.x

Allen, K. J., Lepp, D., Mckellar, R. C., and Griffiths, M. W. (2008). Examination of stress and virulence gene expression in Escherichia coli O157:H7 using targeted microarray analysis. Foodborne Pathog. Dis. 5, 437-447. doi: 10.1089/fpd.2008.0100

Altekruse, S. F., Stern, N. J., Fields, P. I., and Swerdlow, D. L. (1999). Campylobacter jejuni-an emerging foodborne pathogen. Emerg. Infect. Dis. 5, 28-35. doi: 10.3201/eid0501.990104

Atack, J. M., Harvey, P., Jones, M. A., and Kelly, D. J. (2008). The Campylobacter jejuni thiol peroxidases Tpx and Bcp both contribute to aerotolerance and peroxide-mediated stress resistance but have distinct substrate specificities. J. Bacteriol. 190, 5279-5290. doi: 10.1128/JB.00100-08

Atack, J. M., and Kelly, D. J. (2008). Contribution of the stereospecific methionine sulphoxide reductases MsrA and MsrB to oxidative and nitrosative stress resistance in the food-borne pathogen Campylobacter jejuni. Microbiology 154, 2219-2230. doi: 10.1099/mic.0.2008/019711-0

Bae, J., Oh, E., and Jeon, B. (2014). Enhanced transmission of antibiotic resistance in Campylobacter jejuni biofilms by natural transformation. Antimicrob. Agents Chemother. 58, 7573-7575. doi: 10.1128/AAC.04066-14

Baillon, M. L., Van Vliet, A. H., Ketley, J. M., Constantinidou, C., and Penn, C. W. (1999). An iron-regulated alkyl hydroperoxide reductase (AhpC) confers aerotolerance and oxidative stress resistance to the microaerophilic pathogen Campylobacter jejuni. J. Bacteriol. 181, 4798-4804.

Beales, N. (2004). Adaptation of microorganisms to cold temperatures, weak acid preservatives, low $\mathrm{pH}$, and osmotic stress: a review. Compr. Rev. Food Sci. Food 3, 1-20. doi: 10.1111/j.1541-4337.2004.tb00057.x

Becker, J., and Craig, E. A. (1994). Heat-shock proteins as molecular chaperones. Eur. J. Biochem. 219, 11-23. doi: 10.1111/j.1432-1033.1994.tb19910.x

Belzer, C., Van Schendel, B. A., Hoogenboezem, T., Kusters, J. G., Hermans, P. W., Van Vliet, A. H., et al. (2011). PerR controls peroxide- and iron-responsive expression of oxidative stress defense genes in Helicobacter hepaticus. Eur. J. Microbiol. Immunol. (Bp) 1, 215-222. doi: 10.1556/EuJMI.1.2011.3.5

Bingham-Ramos, L. K., and Hendrixson, D. R. (2008). Characterization of two putative cytochrome $\mathrm{c}$ peroxidases of Campylobacter jejuni involved in promoting commensal colonization of poultry. Infect. Immun. 76, 1105-1114. doi: 10.1128/IAI.01430-07

Birk, T., Wik, M. T., Lametsch, R., and Knochel, S. (2012). Acid stress response and protein induction in Campylobacter jejuni isolates with different acid tolerance. BMC Microbiol. 12:174. doi: 10.1186/1471-2180-12-174

Blankenship, L. C., and Craven, S. E. (1982). Campylobacter jejuni survival in chicken meat as a function of temperature. Appl. Environ. Microbiol. 44, 88-92.

Bogosian, G., Aardema, N. D., Bourneuf, E. V., Morris, P. J., and O'neil, J. P. (2000). Recovery of hydrogen peroxide-sensitive culturable cells of Vibrio vulnificus gives the appearance of resuscitation from a viable but nonculturable state. J. Bacteriol. 182, 5070-5075. doi: 10.1128/JB.182.18.5070-5075.2000

Bolton, F. J., Hinchliffe, P. M., Coates, D., and Robertson, L. (1982). A most probable number method for estimating small numbers of campylobacters in water. J. Hyg. (Lond.) 89, 185-190. doi: 10.1017/S0022172400070716

Brenner, D. J., and Staley, J. T. (2005). "Bergey's manual of systematic bacteriology," in The Proteobacteria. Part C. The Alpha-, Beta-, Selta-, and Epsilonproteobacteria, Vol. 2, 2nd Edn, eds G. Garrity, D. J. Brenner, N. R. Krieg, and J. T. Staley (New York, NY: Springer). from mechanisms reported in other foodborne pathogens. Investigation of molecular mechanisms for oxidative stress resistance in $C$. jejuni has been greatly facilitated by the availability of improved experimental techniques. Further characterization of the mechanisms for oxidative stress resistance and regulation will tell us how this fastidious microaerophilic pathogen survives in stress conditions and causes such huge problems in food safety.

Browne, N., and Dowds, B. (2001). Heat and salt stress in the food pathogen Bacillus cereus. J. Appl. Microbiol. 91, 1085-1094. doi: 10.1046/j.13652672.2001.01478.x

Bsat, N., Herbig, A., Casillas-Martinez, L., Setlow, P., and Helmann, J. D. (1998). Bacillus subtilis contains multiple Fur homologues: identification of the iron uptake (Fur) and peroxide regulon (PerR) repressors. Mol. Microbiol. 29, 189-198. doi: 10.1046/j.1365-2958.1998.00921.x

Butcher, J., Sarvan, S., Brunzelle, J. S., Couture, J. F., and Stintzi, A. (2012). Structure and regulon of Campylobacter jejuni ferric uptake regulator Fur define apo-Fur regulation. Proc. Natl. Acad. Sci. U.S.A. 109, 10047-10052. doi: 10.1073/pnas.1118321109

Cameron, A., Frirdich, E., Huynh, S., Parker, C. T., and Gaynor, E. C. (2012). Hyperosmotic stress response of Campylobacter jejuni. J. Bacteriol. 194, 6116-6130. doi: 10.1128/JB.01409-12

Capozzi, V., Fiocco, D., Amodio, M. L., Gallone, A., and Spano, G. (2009). Bacterial stressors in minimally processed food. Int. J. Mol. Sci. 10, 3076-3105. doi: 10.3390/ijms10073076

Carpenter, C. D., Cooley, B. J., Needham, B. D., Fisher, C. R., Trent, M. S., Gordon, V., et al. (2014). The Vps/VacJ ABC transporter is required for intercellular spread of Shigella flexneri. Infect. Immun. 82, 660-669. doi: 10.1128/IAI.01057-13

CDC. (2014). Foodborne Diseases Active Surveillance Network (FoodNet). Available at: http://www.cdc.gov/foodnet/data/trends/trends-2013.html [accessed May 15, 2015].

Chen, Z., and Jiang, X. (2014). Microbiological safety of chicken litter or chicken litter-based organic fertilizers: a review. Agriculture 4, 1-29. doi: 10.3390/agriculture4010001

Chiang, S. M., and Schellhorn, H. E. (2012). Regulators of oxidative stress response genes in Escherichia coli and their functional conservation in bacteria. Arch. Biochem. Biophys. 525, 161-169. doi: 10.1016/j.abb.2012.02.007

Choi, S. H., Baumler, D. J., and Kaspar, C. W. (2000). Contribution of dps to acid stress tolerance and oxidative stress tolerance in Escherichia coli O157: H7. Appl. Environ. Microbiol. 66, 3911-3916. doi: 10.1128/AEM.66.9.3911-3916.2000

Chowdhury, R., Sahu, G. K., and Das, J. (1996). Stress response in pathogenic bacteria. J. Biosci. 21, 149-160. doi: 10.1007/BF02703105

Chung, H., Bang, W., and Drake, M. (2006). Stress response of Escherichia coli. Compr. Rev. Food Sci. Food 5, 52-64. doi: 10.1111/j.1541-4337.2006.00002.x

Day, W. A. Jr., Sajecki, J. L., Pitts, T. M., and Joens, L. A. (2000). Role of catalase in Campylobacter jejuni intracellular survival. Infect. Immun. 68, 6337-6345. doi: 10.1128/IAI.68.11.6337-6345.2000

den Besten, H. M., Mols, M., Moezelaar, R., Zwietering, M. H., and Abee, T. (2009). Phenotypic and transcriptomic analyses of mildly and severely salt-stressed Bacillus cereus ATCC 14579 cells. Appl. Environ. Microbiol. 75, 4111-4119. doi: 10.1128/AEM.02891-08

Elvers, K. T., and Park, S. F. (2002). Quorum sensing in Campylobacter jejuni: detection of a luxS encoded signalling molecule. Microbiology 148, 1475-1481.

Endtz, H. P., Vliegenthart, J. S., Vandamme, P., Weverink, H. W., Van Den Braak, N. P., Verbrugh, H. A., et al. (1997). Genotypic diversity of Campylobacter lari isolated from mussels and oysters in The Netherlands. Int. J. Food Microbiol. 34, 79-88. doi: 10.1016/S0168-1605(96)01174-9

Ezraty, B., Aussel, L., and Barras, F. (2005). Methionine sulfoxide reductases in prokaryotes. Biochim. Biophys. Acta 1703, 221-229. doi: 10.1016/j.bbapap.2004.08.017

Feld, L., Knudsen, G. M., and Gram, L. (2012). Bactericidal antibiotics do not appear to cause oxidative stress in Listeria monocytogenes. Appl. Environ. Microbiol. 78, 4353-4357. doi: 10.1128/AEM.00324-12 
Fields, J. A., and Thompson, S. A. (2008). Campylobacter jejuni CsrA mediates oxidative stress responses, biofilm formation, and host cell invasion. J. Bacteriol. 190, 3411-3416. doi: 10.1128/JB.01928-07

Fields, J. A., and Thompson, S. A. (2012). Campylobacter jejuni CsrA complements an Escherichia coli csrA mutation for the regulation of biofilm formation, motility and cellular morphology but not glycogen accumulation. BMC Microbiol. 12:233. doi: 10.1186/1471-2180-12-233

Flint, A., Sun, Y. Q., Butcher, J., Stahl, M., Huang, H., and Stintzi, A. (2014). Phenotypic screening of a targeted mutant library reveals Campylobacter jejuni defenses against oxidative stress. Infect. Immun. 82, 2266-2275. doi: 10.1128/IAI.01528-13

Flint, A., Sun, Y. Q., and Stintzi, A. (2012). Cj1386 is an ankyrin-containing protein involved in heme trafficking to catalase in Campylobacter jejuni. J. Bacteriol. 194, 334-345. doi: 10.1128/JB.05740-11

Frost, J. A., Gillespie, I. A., and O'brien, S. J. (2002). Public health implications of Campylobacter outbreaks in England and Wales, 1995-9: epidemiological and microbiological investigations. Epidemiol. Infect. 128, 111-118. doi: 10.1017/S0950268802006799

Fuangthong, M., Herbig, A. F., Bsat, N., and Helmann, J. D. (2002). Regulation of the Bacillus subtilis fur and perR genes by PerR: not all members of the PerR regulon are peroxide inducible. J. Bacteriol. 184, 3276-3286. doi: 10.1128/JB.184.12.3276-3286.2002

Fux, C., Costerton, J., Stewart, P., and Stoodley, P. (2005). Survival strategies of infectious biofilms. Trends Microbiol. 13, 34-40. doi: 10.1016/j.tim.2004.11.010

Garénaux, A., Guillou, S., Ermel, G., Wren, B., Federighi, M., and Ritz, M. (2008a). Role of the Cj1371 periplasmic protein and the Cj0355c twocomponent regulator in the Campylobacter jejuni NCTC 11168 response to oxidative stress caused by paraquat. Res. Microbiol. 159, 718-726. doi: 10.1016/j.resmic.2008.08.001

Garénaux, A., Jugiau, F., Rama, F., De Jonge, R., Denis, M., Federighi, M., et al. (2008b). Survival of Campylobacter jejuni strains from different origins under oxidative stress conditions: effect of temperature. Curr. Microbiol. 56, 293-297. doi: $10.1007 /$ s00284-007-9082-8

Garénaux, A., Ritz, M., Jugiau, F., Rama, F., Federighi, M., and De Jonge, R. (2009). Role of oxidative stress in C. jejuni inactivation during freeze-thaw treatment. Curr. Microbiol. 58, 134-138. doi: 10.1007/s00284-008-9289-3

Giard, J. C., Hartke, A., Flahaut, S., Benachour, A., Boutibonnes, P., and Auffray, Y. (1996). Starvation-induced multiresistance in Enterococcus faecalis JH2-2. Curr. Microbiol. 32, 264-271. doi: 10.1007/s002849900048

Grant, K. A., and Park, S. F. (1995). Molecular characterization of katA from Campylobacter jejuni and generation of a catalase-deficient mutant of Campylobacter coli by interspecific allelic exchange. Microbiology 141(Pt 6), 1369-1376. doi: 10.1099/13500872-141-6-1369

Greenberg, J. T., Monach, P., Chou, J. H., Josephy, P. D., and Demple, B. (1990). Positive control of a global antioxidant defense regulon activated by superoxidegenerating agents in Escherichia coli. Proc. Natl. Acad. Sci. U.S.A. 87, 6181-6185. doi: $10.1073 /$ pnas.87.16.6181

Gu, M., and Imlay, J. A. (2011). The SoxRS response of Escherichia coli is directly activated by redox-cycling drugs rather than by superoxide. Mol. Microbiol. 79, 1136-1150. doi: 10.1111/j.1365-2958.2010.07520.x

Gundogdu, O., Mills, D. C., Elmi, A., Martin, M. J., Wren, B. W., and Dorrell, N. (2011). The Campylobacter jejuni transcriptional regulator Cj1556 plays a role in the oxidative and aerobic stress response and is important for bacterial survival in vivo. J. Bacteriol. 193, 4238-4249. doi: 10.1128/JB.0 5189-11

Guo, M. S., and Gross, C. A. (2014). Stress-induced remodeling of the bacterial proteome. Curr. Biol. 24, R424-R434. doi: 10.1016/j.cub.2014. 03.023

Hall-Stoodley, L., and Stoodley, P. (2005). Biofilm formation and dispersal and the transmission of human pathogens. Trends Microbiol. 13, 7-10. doi: 10.1016/j.tim.2004.11.004

Han, K., Jang, S. S., Choo, E., Heu, S., and Ryu, S. (2007). Prevalence, genetic diversity, and antibiotic resistance patterns of Campylobacter jejuni from retail raw chickens in Korea. Int. J. Food Microbiol. 114, 50-59. doi: 10.1016/j.ijfoodmicro.2006.10.042

Hazeleger, W. C., Wouters, J. A., Rombouts, F. M., and Abee, T. (1998). Physiological activity of Campylobacter jejuni far below the minimal growth temperature. Appl. Environ. Microbiol. 64, 3917-3922.
He, Y., Frye, J. G., Strobaugh, T. P., and Chen, C. Y. (2008). Analysis of AI-2/LuxSdependent transcription in Campylobacter jejuni strain 81-176. Foodborne Pathog. Dis. 5, 399-415. doi: 10.1089/fpd.2008.0106

Helmann, J. D. (2014). Specificity of metal sensing: iron and manganese homeostasis in Bacillus subtilis. J. Biol. Chem. 289, 28112-28120. doi: 10.1074/jbc.R114.587071

Hendrixson, D. R., Akerley, B. J., and Dirita, V. J. (2001). Transposon mutagenesis of Campylobacter jejuni identifies a bipartite energy taxis system required for motility. Mol. Microbiol. 40, 214-224. doi: 10.1046/j.1365-2958.2001.02376.x

Hendrixson, D. R., and DiRita, V. J. (2004). Identification of Campylobacter jejuni genes involved in commensal colonization of the chick gastrointestinal tract. Mol. Microbiol. 52, 471-484. doi: 10.1111/j.1365-2958.2004.03988.x

Hengge-Aronis, R. (2002). Recent insights into the general stress response regulatory network in Escherichia coli. J. Mol. Microbiol. Biotechnol. 4, 341-346.

Hill, C., O'driscoll, B., and Booth, I. (1995). Acid adaptation and food poisoning microorganisms. Int. J. Food Microbiol. 28, 245-254. doi: 10.1016/01681605(95)00060-7

Holmes, K., Mulholland, F., Pearson, B. M., Pin, C., Mcnicholl-Kennedy, J., Ketley, J. M., et al. (2005). Campylobacter jejuni gene expression in response to iron limitation and the role of Fur. Microbiology 151, 243-257. doi: 10.1099/mic.0.27412-0

Hudson, J. A., Nicol, C., Wright, J., Whyte, R., and Hasell, S. K. (1999). Seasonal variation of Campylobacter types from human cases, veterinary cases, raw chicken, milk and water. J. Appl. Microbiol. 87, 115-124. doi: 10.1046/j.13652672.1999.00806.x

Huergo, L. F., Rahman, H., Ibrahimovic, A., Day, C. J., and Korolik, V. (2013). Campylobacter jejuni Dps protein binds DNA in the presence of iron or hydrogen peroxide. J. Bacteriol. 195, 1970-1978. doi: 10.1128/JB.00059-13

Hughes, R. A., and Cornblath, D. R. (2005). Guillain-Barré syndrome. Lancet 366, 1653-1666. doi: 10.1016/S0140-6736(05)67665-9

Humphrey, T., O’brien, S., and Madsen, M. (2007). Campylobacters as zoonotic pathogens: a food production perspective. Int. J. Food Microbiol. 117, 237-257. doi: 10.1016/j.ijfoodmicro.2007.01.006

Hwang, S., Jeon, B., Yun, J., and Ryu, S. (2011a). Roles of RpoN in the resistance of Campylobacter jejuni under various stress conditions. BMC Microbiol. 11:207. doi: 10.1186/1471-2180-11-207

Hwang, S., Kim, M., Ryu, S., and Jeon, B. (2011b). Regulation of oxidative stress response by CosR, an essential response regulator in Campylobacter jejuni. PLoS ONE 6:e22300. doi: 10.1371/journal.pone.0022300

Hwang, S., Miller, W. G., Ryu, S., and Jeon, B. (2014). Divergent distribution of the sensor kinase CosS in non-thermotolerant Campylobacter species and its functional incompatibility with the response regulator CosR of Campylobacter jejuni. PLoS ONE 9:e89774. doi: 10.1371/journal.pone.0089774

Hwang, S., Ryu, S., and Jeon, B. (2013). Roles of the superoxide dismutase SodB and the catalase KatA in the antibiotic resistance of Campylobacter jejuni. J. Antibiot. (Tokyo) 66, 351-353. doi: 10.1038/ja.2013.20

Hwang, S., Zhang, Q., Ryu, S., and Jeon, B. (2012). Transcriptional regulation of the CmeABC multidrug efflux pump and the KatA catalase by CosR in Campylobacter jejuni. J. Bacteriol. 194, 6883-6891. doi: 10.1128/JB.01636-12

Imlay, J. A. (2003). Pathways of oxidative damage. Annu. Rev. Microbiol. 57, 395-418. doi: 10.1146/annurev.micro.57.030502.090938

Imlay, J. A. (2008). Cellular defenses against superoxide and hydrogen peroxide. Annu. Rev. Biochem. 77, 755-776. doi: 10.1146/annurev.biochem.77.061606.161055

Imlay, J. A. (2015). Diagnosing oxidative stress in bacteria: not as easy as you might think. Curr. Opin. Microbiol. 24, 124-131. doi: 10.1016/j.mib.2015.01.004

Ishikawa, T., Mizunoe, Y., Kawabata, S., Takade, A., Harada, M., Wai, S. N., et al. (2003). The iron-binding protein Dps confers hydrogen peroxide stress resistance to Campylobacter jejuni. J. Bacteriol. 185, 1010-1017. doi: 10.1128/JB.185.3.1010-1017.2003

Jackson, D. N., Davis, B., Tirado, S. M., Duggal, M., Van Frankenhuyzen, J. K., Deaville, D., et al. (2009). Survival mechanisms and culturability of Campylobacter jejuni under stress conditions. Antonie Van Leeuwenhoek 96, 377-394. doi: 10.1007/s10482-009-9378-8

Jacobson, F. S., Morgan, R. W., Christman, M. F., and Ames, B. N. (1989). An alkyl hydroperoxide reductase from Salmonella typhimurium involved in the defense of DNA against oxidative damage. Purification and properties. J. Biol. Chem. 264, 1488-1496 
Jenkins, D. E., Chaisson, S. A., and Matin, A. (1990). Starvation-induced cross protection against osmotic challenge in Escherichia coli. J. Bacteriol. 172, 2779-2781.

Jenkins, D. E., Schultz, J. E., and Matin, A. (1988). Starvation-induced cross protection against heat or $\mathrm{H}_{2} \mathrm{O}_{2}$ challenge in Escherichia coli. J. Bacteriol. 170, 3910-3914.

Jeon, B., Muraoka, W. T., and Zhang, Q. (2010). Advances in Campylobacter biology and implications for biotechnological applications. Microb. Biotechnol. 3, 242-258. doi: 10.1111/j.1751-7915.2009.00118.x

Jeon, B., Wang, Y., Hao, H., Barton, Y. W., and Zhang, Q. (2011). Contribution of CmeG to antibiotic and oxidative stress resistance in Campylobacter jejuni. J. Antimicrob. Chemother. 66, 79-85. doi: 10.1093/jac/dkq418

Jeon, B., and Zhang, Q. (2009). Sensitization of Campylobacter jejuni to fluoroquinolone and macrolide antibiotics by antisense inhibition of the CmeABC multidrug efflux transporter. J. Antimicrob. Chemother. 63, 946-948. doi: $10.1093 / \mathrm{jac} / \mathrm{dkp} 067$

Jeong, K. C., Hung, K. F., Baumler, D. J., Byrd, J. J., and Kaspar, C. W. (2008). Acid stress damage of DNA is prevented by Dps binding in Escherichia coli O157: H7. BMC Microbiol. 8:181. doi: 10.1186/1471-2180-8-181

Jonas, R., Kittl, S., Overesch, G., and Kuhnert, P. (2015). Genotypes and antibiotic resistance of bovine Campylobacter and their contribution to human campylobacteriosis. Epidemiol. Infect. 143, 2373-2380. doi: 10.1017/S095026881400341

Jorgensen, F., Bailey, R., Williams, S., Henderson, P., Wareing, D. R., Bolton, F. J., et al. (2002). Prevalence and numbers of Salmonella and Campylobacter spp. on raw, whole chickens in relation to sampling methods. Int. J. Food Microbiol. 76, 151-164. doi: 10.1016/S0168-1605(02)00027-2

Kaakoush, N. O., Baar, C., Mackichan, J., Schmidt, P., Fox, E. M., Schuster, S. C., et al. (2009). Insights into the molecular basis of the microaerophily of three Campylobacterales: a comparative study. Antonie Van Leeuwenhoek 96, 545-557. doi: 10.1007/s10482-009-9370-3

Kalmokoff, M., Lanthier, P., Tremblay, T.-L., Foss, M., Lau, P. C., Sanders, G., et al. (2006). Proteomic analysis of Campylobacter jejuni 11168 biofilms reveals a role for the motility complex in biofilm formation. J. Bacteriol. 188, 4312-4320. doi: 10.1128/JB.01975-05

Kassem, II, Chandrashekhar, K., and Rajashekara, G. (2013). Of energy and survival incognito: a relationship between viable but non-culturable cells formation and inorganic polyphosphate and formate metabolism in Campylobacter jejuni. Front. Microbiol. 4:183. doi: 10.3389/fmicb.2013.00183

Kim, J. C., Oh, E., Hwang, S., Ryu, S., and Jeon, B. (2015). Non-selective regulation of peroxide and superoxide resistance genes by PerR in Campylobacter jejuni. Front. Microbiol. 6:126. doi: 10.3389/fmicb.2015.00126

Kim, M., Hwang, S., Ryu, S., and Jeon, B. (2011). Regulation of perR expression by iron and PerR in Campylobacter jejuni. J. Bacteriol. 193, 6171-6178. doi: 10.1128/JB.05493-11

Kim, Y. H., Lee, Y., Kim, S., Yeom, J., Yeom, S., Seok Kim, B., et al. (2006). The role of periplasmic antioxidant enzymes (superoxide dismutase and thiol peroxidase) of the Shiga toxin-producing Escherichia coli O157: H7 in the formation of biofilms. Proteomics 6, 6181-6193. doi: 10.1002/pmic.200600320

Kohanski, M. A., Dwyer, D. J., Hayete, B., Lawrence, C. A., and Collins, J. J. (2007). A common mechanism of cellular death induced by bactericidal antibiotics. Cell 130, 797-810. doi: 10.1016/j.cell.2007.06.049

Kong, I. S., Bates, T. C., Hulsmann, A., Hassan, H., Smith, B. E., and Oliver, J. D. (2004). Role of catalase and oxyR in the viable but nonculturable state of Vibrio vulnificus. FEMS Microbiol. Ecol. 50, 133-142. doi: 10.1016/j.femsec.2004.06.004

Kramer, J. M., Frost, J. A., Bolton, F. J., and Wareing, D. R. (2000). Campylobacter contamination of raw meat and poultry at retail sale: identification of multiple types and comparison with isolates from human infection. J. Food Prot. 63, 1654-1659.

Kültz, D. (2005). Molecular and evolutionary basis of the cellular stress response. Annu. Rev. Physiol. 67, 225-257. doi: 10.1146/annurev.physiol.67.040403.103635

Lee, J. W., and Helmann, J. D. (2006). The PerR transcription factor senses $\mathrm{H}_{2} \mathrm{O}_{2}$ by metal-catalysed histidine oxidation. Nature 440, 363-367. doi: 10.1038 /nature 04537

Lindsay, J. A. (1997). Chronic sequelae of foodborne disease. Emerg. Infect. Dis. 3, 443-452. doi: 10.3201/eid0304.970405
Liu, Y., and Imlay, J. A. (2013). Cell death from antibiotics without the involvement of reactive oxygen species. Science 339, 1210-1213. doi: $10.1126 /$ science. 1232751

Luangtongkum, T., Jeon, B., Han, J., Plummer, P., Logue, C. M., and Zhang, Q. (2009). Antibiotic resistance in Campylobacter: emergence, transmission and persistence. Fut. Microbiol. 4, 189-200. doi: 10.2217/17460913.4.2.189

Lushchak, V. I. (2011). Adaptive response to oxidative stress: bacteria, fungi, plants and animals. Comp. Biochem. Physiol. C Toxicol. Pharmacol. 153, 175-190. doi: 10.1016/j.cbpc.2010.10.004

Marchant, J., Wren, B., and Ketley, J. (2002). Exploiting genome sequence: predictions for mechanisms of Campylobacter chemotaxis. Trends Microbiol. 10, 155-159. doi: 10.1016/S0966-842X(02)02323-5

Mazzotta, A. S. (2000). D- and Z-values of Salmonella in ground chicken breast meat. J. Food Safety 20, 217-223. doi: 10.1111/j.1745-4565.2000.tb 00300.x

Mizunoe, Y., Wai, S. N., Takade, A., and Yoshida, S.-I. (1999). Restoration of culturability of starvation-stressed and low-temperature-stressed Escherichia coli $\mathrm{O} 157$ cells by using $\mathrm{H}_{2} \mathrm{O}_{2}$-degrading compounds. Arch. Microbiol. 172, 63-67. doi: 10.1007/s002030050741

Mongkolsuk, S., and Helmann, J. D. (2002). Regulation of inducible peroxide stress responses. Mol. Microbiol. 45, 9-15. doi: 10.1046/j.1365-2958.2002.03015.x

Murphy, C., Carroll, C., and Jordan, K. N. (2003). Induction of an adaptive tolerance response in the foodborne pathogen, Campylobacter jejuni. FEMS Microbiol. Lett. 223, 89-93. doi: 10.1016/S0378-1097(03)00348-3

Murphy, C., Carroll, C., and Jordan, K. N. (2006). Environmental survival mechanisms of the foodborne pathogen Campylobacter jejuni. J. Appl. Microbiol. 100, 623-632. doi: 10.1111/j.1365-2672.2006.02903.x

Oh, E., and Jeon, B. (2014). Role of alkyl hydroperoxide reductase (AhpC) in the biofilm formation of Campylobacter jejuni. PLOS ONE 9:e87312. doi: 10.1371/journal.pone.0087312

Oh, E., Mcmullen, L., and Jeon, B. (2015). Impact of oxidative stress defense on bacterial survival and morphological change in Campylobacter jejuni under aerobic conditions. Front. Microbiol. 6:295. doi: 10.3389/fmicb.2015.00295

Oliver, J. D. (2010). Recent findings on the viable but nonculturable state in pathogenic bacteria. FEMS Microbiol. Rev. 34, 415-425. doi: 10.1111/j.15746976.2009.00200.x

Palyada, K., Sun, Y. Q., Flint, A., Butcher, J., Naikare, H., and Stintzi, A. (2009). Characterization of the oxidative stress stimulon and PerR regulon of Campylobacter jejuni. BMC Genom. 10:481. doi: 10.1186/1471-2164-10-481

Palyada, K., Threadgill, D., and Stintzi, A. (2004). Iron acquisition and regulation in Campylobacter jejuni. J. Bacteriol. 186, 4714-4729. doi: 10.1128/JB.186.14.47144729.2004

Park, S. F. (2002). The physiology of Campylobacter species and its relevance to their role as foodborne pathogens. Int. J. Food Microbiol. 74, 177-188. doi: 10.1016/S0168-1605(01)00678-X

Parkhill, J., Wren, B. W., Mungall, K., Ketley, J. M., Churcher, C., Basham, D., et al. (2000). The genome sequence of the food-borne pathogen Campylobacter jejuni reveals hypervariable sequences. Nature 403, 665-668. doi: 10.1038/35001088

Parsek, M. R., and Singh, P. K. (2003). Bacterial biofilms: an emerging link to disease pathogenesis. Annu. Rev. Microbiol. 57, 677-701. doi: 10.1146/annurev.micro.57.030502.090720

Pesci, E. C., Cottle, D. L., and Pickett, C. L. (1994). Genetic, enzymatic, and pathogenic studies of the iron superoxide dismutase of Campylobacter jejuni. Infect. Immun. 62, 2687-2694.

Pomposiello, P. J., Bennik, M. H., and Demple, B. (2001). Genomewide transcriptional profiling of the Escherichia coli responses to superoxide stress and sodium salicylate. J. Bacteriol. 183, 3890-3902. doi: 10.1128/JB.183.13.3890-3902.2001

Raphael, B. H., Pereira, S., Flom, G. A., Zhang, Q., Ketley, J. M., and Konkel, M. E. (2005). The Campylobacter jejuni response regulator, CbrR, modulates sodium deoxycholate resistance and chicken colonization. J. Bacteriol. 187, 3662-3670. doi: 10.1128/JB.187.11.3662-3670.2005

Reuter, M., Mallett, A., Pearson, B. M., and Van Vliet, A. H. (2010). Biofilm formation by Campylobacter jejuni is increased under aerobic conditions. Appl. Environ. Microbiol. 76, 2122-2128. doi: 10.1128/AEM.01878-09

Ruiz-Palacios, G. M. (2007). The health burden of Campylobacter infection and the impact of antimicrobial resistance: playing chicken. Clin. Infect. Dis. 44, 701-703. doi: 10.1086/509936 
Samuel, M. C., Vugia, D. J., Shallow, S., Marcus, R., Segler, S., Mcgivern, T., et al. (2004). Epidemiology of sporadic Campylobacter infection in the United States and declining trend in incidence, FoodNet 1996-1999. Clin. Infect. Dis. 38(Suppl. 3), S165-S174. doi: 10.1086/381583

Scharff, R. L. (2012). Economic burden from health losses due to foodborne illness in the United States. J. Food Prot. 75, 123-131. doi: 10.4315/0362-028X.JFP11-058

Seaver, L. C., and Imlay, J. A. (2001). Alkyl hydroperoxide reductase is the primary scavenger of endogenous hydrogen peroxide in Escherichia coli. J. Bacteriol. 183, 7173-7181. doi: 10.1128/JB.183.24.7173-7181.2001

Serichantalergs, O., Dalsgaard, A., Bodhidatta, L., Krasaesub, S., Pitarangsi, C., Srijan, A., et al. (2007). Emerging fluoroquinolone and macrolide resistance of Campylobacter jejuni and Campylobacter coli isolates and their serotypes in Thai children from 1991 to 2000. Epidemiol. Infect. 135, 1299-1306. doi: $10.1017 /$ S0950268807008096

Stead, D., and Park, S. F. (2000). Roles of Fe superoxide dismutase and catalase in resistance of Campylobacter coli to freeze-thaw stress. Appl. Environ. Microbiol. 66, 3110-3112. doi: 10.1128/AEM.66.7.3110-3112.2000

Stintzi, A. (2003). Gene expression profile of Campylobacter jejuni in response to growth temperature variation. J. Bacteriol. 185, 2009-2016. doi: 10.1128/JB.185.6.2009-2016.2003

Stintzi, A., and Whitworth, L. (2003). Investigation of the Campylobacter jejuni cold-shock response by global transcript profiling. Genome Lett. 2, 18-27.

Storz, G., and Imlay, J. A. (1999). Oxidative stress. Curr. Opin. Microbiol. 2, 188-194. doi: 10.1016/S1369-5274(99)80033-2

Storz, G., Jacobson, F. S., Tartaglia, L. A., Morgan, R. W., Silveira, L. A., and Ames, B. N. (1989). An alkyl hydroperoxide reductase induced by oxidative stress in Salmonella typhimurium and Escherichia coli: genetic characterization and cloning of ahp. J. Bacteriol. 171, 2049-2055.

Suzuki, T., Murai, T., Fukuda, I., Tobe, T., Yoshikawa, M., and Sasakawa, C. (1994). Identification and characterization of a chromosomal virulence gene, vacJ, required for intercellular spreading of Shigella flexneri. Mol. Microbiol. 11, 31-41. doi: 10.1111/j.1365-2958.1994.tb00287.x

Svensson, S. L., Davis, L. M., Mackichan, J. K., Allan, B. J., Pajaniappan, M., Thompson, S. A., et al. (2009). The CprS sensor kinase of the zoonotic pathogen Campylobacter jejuni influences biofilm formation and is required for optimal chick colonization. Mol. Microbiol. 71, 253-272. doi: 10.1111/j.13652958.2008.06534.x

Svensson, S. L., Hyunh, S., Parker, C. T., and Gaynor, E. C. (2015). The Campylobacter jejuni CprRS two-component regulatory system regulates aspects of the cell envelope. Mol. Microbiol. 96, 189-209. doi: $10.1111 / \mathrm{mmi} .12927$

Tao, K., Fujita, N., and Ishihama, A. (1993). Involvement of the RNA polymerase alpha subunit $\mathrm{C}$-terminal region in co-operative interaction and transcriptional activation with OxyR protein. Mol. Microbiol. 7, 859-864. doi: 10.1111/j.13652958.1993.tb01176.x

Taylor, E. V., Herman, K. M., Ailes, E. C., Fitzgerald, C., Yoder, J. S., Mahon, B. E., et al. (2013). Common source outbreaks of Campylobacter infection in the USA, 1997-2008. Epidemiol. Infect. 141, 987-996. doi: 10.1017/S0950268812001744

Thomas, C., Hill, D., and Mabey, M. (2002). Culturability, injury and morphological dynamics of thermophilic Campylobacter spp. within a laboratory-based aquatic model system. J. Appl. Microbiol. 92, 433-442. doi: 10.1046/j.1365-2672.2002.01550.x

Thomas, C., Hill, D. J., and Mabey, M. (1999). Evaluation of the effect of temperature and nutrients on the survival of Campylobacter spp. in water microcosms. J. Appl. Microbiol. 86, 1024-1032. doi: 10.1046/j.13652672.1999.00789.x

Thomas, M. K., Majowicz, S. E., Sockett, P. N., Fazil, A., Pollari, F., Dore, K., et al. (2006). Estimated numbers of community cases of illness due to Salmonella, Campylobacter and Verotoxigenic Escherichia coli: pathogenspecific community rates. Can. J. Infect. Dis. Med. Microbiol. 17, 229-234.
Tsaneva, I. R., and Weiss, B. (1990). soxR, a locus governing a superoxide response regulon in Escherichia coli K-12. J. Bacteriol. 172, 4197-4205.

van Vliet, A. H., Baillon, M.-L. A., Penn, C. W., and Ketley, J. M. (2001). The ironinduced ferredoxin FdxA of Campylobacter jejuni is involved in aerotolerance. FEMS Microbiol. Lett. 196, 189-193. doi: 10.1016/S0378-1097(01)00067-2

van Vliet, A. H., Baillon, M. L., Penn, C. W., and Ketley, J. M. (1999). Campylobacter jejuni contains two fur homologs: characterization of ironresponsive regulation of peroxide stress defense genes by the PerR repressor. J. Bacteriol. 181, 6371-6376.

van Vliet, A. H., Ketley, J. M., Park, S. F., and Penn, C. W. (2002). The role of iron in Campylobacter gene regulation, metabolism and oxidative stress defense. FEMS Microbiol. Rev. 26, 173-186. doi: 10.1111/j.1574-6976.2002.tb00609.x

van Vliet, A. H., Wooldridge, K. G., and Ketley, J. M. (1998). Iron-responsive gene regulation in a Campylobacter jejuni fur mutant. J. Bacteriol. 180, 5291-5298.

Wesche, A. M., Gurtler, J. B., Marks, B. P., and Ryser, E. T. (2009). Stress, sublethal injury, resuscitation, and virulence of bacterial foodborne pathogens. J. Food Prot. 72, 1121-1138.

Wilson, I. G., and Moore, J. E. (1996). Presence of Salmonella spp. and Campylobacter spp. in shellfish. Epidemiol. Infect. 116, 147-153. doi: $10.1017 /$ S0950268800052377

Winterbourn, C. C., Hawkins, R. E., Brian, M., and Carrell, R. W. (1975). The estimation of red cell superoxide dismutase activity. J. Lab. Clin. Med. 85, 337-341.

Wouters, J. A., Rombouts, F. M., Kuipers, O. P., De Vos, W. M., and Abee, T. (2000). The role of cold-shock proteins in low-temperature adaptation of food-related bacteria. Syst. Appl. Microbiol. 23, 165-173. doi: 10.1016/S07232020(00)80001-6

Wright, J. A., Grant, A. J., Hurd, D., Harrison, M., Guccione, E. J., Kelly, D. J., et al. (2009). Metabolite and transcriptome analysis of Campylobacter jejuni in vitro growth reveals a stationary-phase physiological switch. Microbiology 155, 80-94. doi: 10.1099/mic.0.021790-0

Yamasaki, M., Igimi, S., Katayama, Y., Yamamoto, S., and Amano, F. (2004). Identification of an oxidative stress-sensitive protein from Campylobacter jejuni, homologous to rubredoxin oxidoreductase/rubrerythrin. FEMS Microbiol. Lett. 235, 57-63. doi: 10.1016/j. femsle.2004.04.012S037810970400271X

Young, K. T., Davis, L. M., and Dirita, V. J. (2007). Campylobacter jejuni: molecular biology and pathogenesis. Nat. Rev. Microbiol. 5, 665-679. doi: $10.1038 /$ nrmicro1718

Zhao, G., Ceci, P., Ilari, A., Giangiacomo, L., Laue, T. M., Chiancone, E., et al. (2002). Iron and hydrogen peroxide detoxification properties of DNA-binding protein from starved cells. A ferritin-like DNA-binding protein of Escherichia coli. J. Biol. Chem. 277, 27689-27696. doi: 10.1074/jbc.M202094200

Zheng, M., Aslund, F., and Storz, G. (1998). Activation of the OxyR transcription factor by reversible disulfide bond formation. Science 279, 1718-1721. doi: $10.1126 /$ science.279.5357.1718

Zheng, M., Wang, X., Templeton, L. J., Smulski, D. R., Larossa, R. A., and Storz, G. (2001). DNA microarray-mediated transcriptional profiling of the Escherichia coli response to hydrogen peroxide. J. Bacteriol. 183, 4562-4570. doi: 10.1128/JB.183.15.4562-4570.2001

Conflict of Interest Statement: The authors declare that the research was conducted in the absence of any commercial or financial relationships that could be construed as a potential conflict of interest.

Copyright (c) $2015 \mathrm{Kim}, \mathrm{Oh}$, Kim and Jeon. This is an open-access article distributed under the terms of the Creative Commons Attribution License (CC BY). The use, distribution or reproduction in other forums is permitted, provided the original author(s) or licensor are credited and that the original publication in this journal is cited, in accordance with accepted academic practice. No use, distribution or reproduction is permitted which does not comply with these terms. 